\title{
'What's in a name? The power of the English language in secondary school science education'
}

\author{
Wilton George Lodge ${ }^{1}$ (D)
}

Received: 9 May 2018 / Accepted: 6 May 2019 / Published online: 4 June 2019

(c) The Author(s) 2019

\begin{abstract}
The global dominance of the English language has led to intense debates with the emergence of studies of English as a lingua franca. These debates can be positioned along a continuum stretching from those who see the spread of English as a force of good representing progress and those who see it as a destructive force of globalisation. Between these two extremes are those who suggest that languages such as Creole and other 'hybrid' languages are essential in particular contexts, while also supporting the use of standardised English in others. Such debates are particularly salient in the context of Jamaica, where the official language and the language of instructions at all levels of schooling is Jamaican Standard English (JSE) but many of the people are first language speakers of Jamaican Creole (JC). Despite its valorisation, JC has not substantially challenged the prestige position of JSE in the Jamaican classroom. Such perspectives have been used to situate and position the English language as a hegemonic force that serves to reinforce inequalities in the teaching and learning of science. Against a background of the Creole-speaking environment in Jamaica, this paper investigates the dominance of English language in secondary school science. Participants were selected from five school types in Jamaica: junior high, private, technical, traditional and upgraded secondary. Data concerning students' and teachers' attitudes and opinions were collected using semi-structured interviews. The results suggest that, despite evidence that attitudes towards JC are changing, it was clear from the student and teacher interviews that JSE continued to dominate scientific discourse in Jamaican classrooms. Evidence of JSE as a hegemonic language was pervasively present throughout the discussions with the participants, with many supporting the use of JSE as the sole medium of instruction in science discourse. The argument that JSE speakers were more intelligent and more likely to be successful resonated with many participants and highlighted an ideological acceptance of the hegemonic order.
\end{abstract}

Keywords Linguistic hegemony · Jamaican Standard English · Jamaican Creole $\cdot$ Science instructions $\cdot$ Bilingualism

Lead Editor: Sara Tolbert.

Wilton George Lodge

wilton_lodge@hotmail.com

1 UCL Institute of Education, London, UK 
Over the last three decades, the dominance of global English has led to fierce debates with the emergence of studies of English as a lingua franca (Crystal 1988; Pennycook 2014; Phillipson 2008). These debates can be situated along a continuum extending from those who see the spread of English as a force of good representing development and advancement (Honey 1997) and those who see it as an injurious force of globalisation (Mair 2013). Amidst these two extremes are those who suggest that languages such as Creole and other 'hybrid' languages are essential in particular contexts, whilst also supporting the use of standardised English in others (Bryan 2010).

It is, however, the spread of English as a contributory factor to many of the world's socio-political and economic inequities that has been the foci of much consideration over the last two decades. Writers such as Ruanni Tupas and Rani Rubdy (2015) and Robert Phillipson (2001) argue that far from being a solution to the dismantling of the imbalances cultivated by globalisation and liberalisation, English is often part of the problem and continues to threaten other cultures. Alistair Pennycook (2014) makes much the same point as Tupas and Rubdy (2015) when he warns that 'Global English' will result in cultural homogenisation that will threaten the existence of non-English speaking peoples' culture. Equally, Schulzke (2014) points to the 'permanent scars' on those who were coerced into learning English by the colonial powers and the linguistic prejudice that now exists in these territories.

A prime example of Pennycook's (2014) argument can be seen in the Anglophone Caribbean territories, where Creole, the language inherited from slave ancestors, has a long history of discrimination as a corrupted and inferior 'dialect' of the more prestigious lexically related Standard English. A case in point is Jamaica, where Jamaican Standard English (JSE), the language of the Anglicist colonial powers, is the language used in formal spheres-government, judicature and in international relations. Yet, Jamaican Creole (JC) is the native-born language of a wide cross section of the population and dominates the social spheres of day-to-day interactions. The existence of such a situation is problematic as most Jamaicans only acquire JSE in the formal school setting, but mastery of it is essential for upward mobility and social advancement.

Science and technology have not been immune from the dominance of 'Global English'. In many countries, scientific production and scholarly interchange are overwhelmingly dominated by English, such that interacting and publishing in some other language is a deliberate sign of a specific agenda. Furthermore, scholars with insufficient written English language proficiency are routinely denied opportunities to share their work in academic journals. This limits their involvement in the global exchange of science information networks. Thus, their ideas and contributions are not only lost to the scientists themselves but are excluded from the wider scientific community.

At the same time, in the field of education, a rich corpus of the literature has underscored the language in which science instruction is delivered as a crucial factor in cognitive learning and achieving science literacy. Zehlia Babaci-Wilhite (2016), for example, argues that students can only acquire a comprehensive and nuanced perception of the natural world when the subject is taught through a language in which they are proficient. BabaciWilhite's argument is not new. Indeed, there is considerable international evidence which suggests that making use of students' home languages improves scientific reasoning and ratiocination, content knowledge and self-efficacy (Brock-Utne 2016).

Taken from this perspective, many Jamaican scholars and, indeed, government officials, with post-colonial, nationalist agendas, have called for more effective communicative strategies that emphasise local contextualisation and which allow students to move from a repressive colonial system of education to a more dynamic and culturally responsive 
education which is applicable to modern Jamaican values, linguistics and a socio-cultural background (Bryan 2010). They argue that the current science curriculum policies, which vigorously promote JSE as the sole language of science instruction, while at the same time suppressing the use of the local vernacular, JC, create a barrier between real-life and classroom experience (Lodge 2018).

Lamentably, Jamaican policymakers have chosen to ignore the sage advice of educational reformers and socio-linguists, to neither promote the language nor include the formal use of JC in science education. As such, JSE has remained the language of scientific knowledge and literacy in Jamaica. This is in spite of the findings of many research studies that have shown that most Jamaicans are first language speakers of JC and are not proficient in using JSE (Bryan 2010).

This paper intends to explore the linguistic hegemony in the Jamaican science classroom, with particular emphasis on the relationship between JSE and JC. My use of the term 'linguistic hegemony' is consistent with that of Debra Suarez (2002), who describes it as a form of power that empowers some languages while disempowering others. In such a formulation, according to Suarez (2002, p. 514), 'linguistic minorities will believe and participate in the subjugation of the minority language to the dominant, to the point where just the dominant language remains.' Thus, linguistic hegemony is maintained through an unequal power relationship between dominant and minority languages. I argue that JSE has had a hegemonic influence which has resulted in the marginalisation of JC in terms of learning in science education. Such hegemonic status and global currency have been used to trump any argument for the elevation of JC and has yielded a homogeneistic and assimilationist attitude towards speakers of JC. This has resulted in the relegation of monolingual JC speakers to second-class citizenship, because their language is considered an unsuitable subject for scientific curricula and classroom discourse.

The hegemonic influence of JSE is evident in the norms and practices of formal science learning environments, where teachers, many of whom, intentionally or unintentionally, fail to acknowledge the significance of the students' home language and cultural experience and encourage them to communicate scientific reasoning and argumentation in JSE. In these classrooms, a student's diverse and perceptive view about the natural and social world is not recognised, listened to and not considered important in the formulation of science instruction.

\section{Language ideologies in Jamaica}

Jamaica, a multiracial and multilingual society, finds itself facing an unusually complicated socio-linguistic situation. After four centuries of English rule, and over 50 years of independence, the country continues to use JSE as its official language of government agencies, business institutions, newspapers and other communication media. At the same time, JC, a language fashioned by the act of colonisation, maintained in an inferior status and contaminated by the valorising practice of the English language, continues to be used by the majority of the population. This linguistic 'schizophrenia' has been the result of an elitist colonial programme that produced bilingual speakers whose social status depended on proficiency in JSE and set a class stigma on the use of JC. Today, the usage of the two languages is so clearly defined that should one be used out of place, a whole set of social and linguistic traditions are disrupted. The sharper national awareness accompanying independence has inspired a new look at these 
languages but because of their separate distinctions, the underlying social questions are still to be resolved.

JC and the period of colonisation are intricately intertwined in the social history of Jamaica, for it was during colonisation that the crucible arose in which this oral language was created. Originally developed as a pidgin, JC is the result of a mixture of various African languages, English and other European languages that developed in and around the English slave factories and trading posts along the west African littoral. For the slaves, JC was not only a means of communicating with overseers, but more importantly a means of communicating with one another. The designs of the colonial overseers to separate tribal members, and hence cut down the slaves' ability to communicate with one another, furthered the use of this lingua franca. As a consequence, the number of Creole speakers in Jamaica increased steadily.

It is therefore important to recognise and understand that JSE was used as a tool for retaining control over the ex-slaves. According to Kathleen Drayton (1990, p. 201) a "political decision was taken [by the Colonial Office] to make the English language the main cultural form of oppression... the aim of which was to use the language of the empire as a kind of cement to bind people to one common aim and destiny, namely the continuance of the empire.' In this formulation, English is inherently civilising, the purveyor of taste, culture and values. Thus, a person skilled in English has traditionally been rewarded with greater opportunities in life. It could take 'him' not only out of his 'village' but also to the UK or USA, the ultimate lands of promise.

The above perspectives have been used to situate and position the English language as a dangerous hegemonic force that serves to reinforce unequal divisions of power based on English proficiency. For many, English and the command of it has been constructed as a powerful apparatus for growth and innovation in a globalized world. Such ideology has given the English language an unparalleled status an undisputable, highly regarded commodification in contemporary forms of liberalised societies. However, while some observers point to the above observations as positive developments for humanity (Honey 1997), others have highlighted the dangers of promoting the English language in this way, to the exclusion of other languages (Mair 2013).

In contemporary Jamaican society, despite the recognition of JC as a language since the 1950s, Creole speech remains disappointedly stigmatized, having been reduced to a mere 'Englishified patwa', fit only for jokes and folklores (Bryan 2010). In fact, so great is the disdain towards JC being spoken in public that in some homes children are routinely scolded or even beaten for speaking it. In my own experience, as a child growing up in Jamaica, an unwritten rule was normalised-while parents habitually spoke JC amongst themselves and to their children, children were not accorded the same custom in response. Instead it was-and still is-expected that children should reply to adults and each other using JSE, both as a symbol of 'value' and for 'practice'. Thus, from a young age the dichotomy of attitudes towards language is systematically regularised in Jamaican children.

More recently, such hegemony has been challenged from within and questions have been raised about using JC in all official settings including in the education system. Prominent Jamaican socio-linguist Hubert Devonish (1986) argues that since 'the language a people communicate in everyday is the most effective for creativity, initiative and productivity' (p. 35), JC must be used in all formal settings. Devonish grounds his analysis of Jamaican language policies in socialist theories of class struggle and argues that language policy for education must challenge the diglossic status quo. However, the Jamaican elites have challenged this position and actively strive to put JC in its 'place', arguing that it 
'does not conform to syntactical rules', or that 'it has not got the kind of vocabulary to handle "serious" matters', or that 'JC is just a hodge-podge of sounds and words'. Those who voice these arguments show a kind of intellectual and emotional myopia based on social prejudice, not linguistic fact.

Nonetheless, there is some evidence to suggest that negative perceptions of the JC may be weakening (Bryan 2010). This change has accompanied an increased acceptance of the significance of the relationship between JC and culture (Christie 2003). Mervyn Alleyne (2005, p. 5) argues that JC 'is one of the main forces contributing to a distinct Jamaican culture and identity.' This has led to an increased use by the English-speaking elites who, through this, demonstrate their loyalty to the nation. In this sense, JC is observed as the language of cultural vitality, occupying an integral role in the retention and transmission of traditional values.

There is, however, a second related but distinct view. This second position recognizes the rich and complex interrelationships of language and power. Central here are two assertions: power is exercised in conversation and other forms of expression between people; language is used as a form of resistance to those in power (in Foucauldian terms). In this sense, JC has been used as a medium of conscious resistance to linguistic imperialism. Here, the importance of story-telling and the oral tradition inherent to African culture is kept alive and serves as a communal mode of resistance. That is, resistance to oppression, social injustices, class prejudice and the various other forms of closure that exist in any society. In this sense, a social reality is created through language and takes on many permutations to challenge hegemony.

\section{Bilingual education}

Interpretation of the plethora of research on bilingual education has been highly contested amongst linguistic scholars (Baker 2011). One reason for such contestation maybe due to the varying interpretation amongst scholars of what such an education should contain. While some scholars see bilingual education as any 'approach directed at bilingual students, irrespective of their educational aims' (May 2008, p. 19), others seek to distinguish between different categories of bilingual programmes-weak and strong (Baker 2011). However, regardless of the theoretical underpinnings, research from both evaluative and comparative analyses have found significant pedagogical advantages of bilingual approaches over monolingual ones. Jim Cummins (1992), for example, in his 'interdependence hypothesis model', demonstrates that children who have a high level of competence in both their first and second languages develop significant cognitive benefits than those with competence in only one language. He emphasised the 'interdependence of literacyrelated or academic skills across languages' (Cummins 1992, p. 39) and argues for children to develop both fluency and competence in second language while continuing to develop competence in their home language. Cummins's argument is supported by researchers such as Raluca Barac and Ellen Biaslystok (2011), who reported that a bilingual-more than a monolingual — education fosters classification skills, concept formation, analogical reasoning and visual-spatial skills.

Since the 1960s, a substantial number of bilingual programmes have been created to support English learners, ranging from classrooms where students receive little or no instruction in their first language to classrooms where both the home language and English are used at all levels of the education system. Between these two extremes are transitional 
bilingual programmes in which the students' home language is used for a period of time, after which students are taught primarily in English. Such programmes are particularly dominant in the USA and are important in helping minority language speakers transition from their home language to English.

While some proponents of transitional bilingual programmes have highlighted several benefits, including bolstering children's self-esteem by using their native language as the medium of instruction, some researchers have been highly critical, arguing that such programmes contribute 'much more to the malady than the remedy in the education of linguistic minorities' (Macswan 2000, p. 20). They point to the failure of these programmes to address the 'varying degrees of socioeconomic marginality and racial or ethnic discrimination' in linguistic minority children (Ovando and Collier 1985, p. 6). Other critics have been quick to point to research evidence which suggests that not only do transitional bilingual programmes fail to teach linguistic minorities standard English, they also fail to promote linguistic equity. In other words, instead of equalising the power of languages they give preference to the dominant language whilst the speakers of the minoritized language receive the reinforced message that their languages are less expressive or lack complexity when compared to more 'standard' languages.

The argument that points to the failure of not only transitional bilingual programmes but bilingual education programmes in general to address social class issues in the education of linguistic minorities has penetrated scholarship on bilingual education since the 1970s. Scholars such as Christine Bratt Paulston (1975) have consistently reminded us that all bilingual education operates in a societal hierarchization of languages. In such a formulation, the dominant language of the internal elite occupies a more privileged position than the minoritized languages. Thus, rather than aligning the power of the languages, most traditional bilingual programmes still promote the dominant language.

\section{Methods}

The research presented in this article is part of a larger multiple methods study examining the accessibility of science instructions in Jamaica. A total of 18 teachers and 30 students were selected for interviews using a purposive sampling approach and were drawn from five school types in Jamaica: junior high, private, technical, traditional and upgraded secondary. These schools were chosen to ensure a wide coverage of student backgrounds and school facilities. Interviews were of two types, group interviews with the students (five groups consisting of six participants) and individual interviews with the teachers.

The interviews were semi-structured and directed by an interview guide that was formulated from the research question: To what extent is secondary school science instruction in Jamaica accessible to their intended audience?

All the interviews lasted for about 30 to $40 \mathrm{~min}$. The interviews were audio-recorded, which provided an accurate account of the spoken language in the interviews, as well as capturing the speed of speech, tone and voice pitch of the participants. These data proved to be very useful in the analysis. Furthermore, the recordings allowed me to transcribe the participants' responses, which was essential for full analysis. An inductive analysis was used to look for themes and commonalties as they emerged from the data. The themes were then extracted from the original categories and placed in individual files using a process of open coding. Some of the early findings were fed back to the participants, so that opportunities for reflection and contemplation could be generated. 
With respect to the students, group interviews were adopted to gain further insights into the linguistic hegemony in Jamaican science classroom. Group interviews have been increasingly used in qualitative research to collect information for a wide range of purposes. However, the main advantage of this approach to the fieldwork in this study was purely practical. Initially, most of the students cited unwillingness to engage in individual interviews but agreed to participate in group discussions after being convinced about the benefits of the research study. Furthermore, some participants were also unwilling to commit to a waiting times schedule for completion of individual interviews. Thus, group interviews were more viable than individual ones.

During the interviews, an informal environment of conversation was developed to make the participants feel comfortable. Students could talk to each other, ask questions and express thoughts without being interrupted. This sometimes made it extremely difficult to keep participants focussed on the topic. Indeed, in one school, the students were more interested in talking about Premier League football than they were about their science instruction. It was only when their teacher intervened that that they refocussed and engaged in discussions of some of the salient issues related to the research questions.

Throughout the interview process, I adopted an understanding attitude towards students and was not critical of them. When students made disparaging remarks about their teachers, I took a non-judgemental stance. Instead, I tried to be understanding but at the same time encouraged the students to conduct the interview in a respectful way. Perhaps the informal nature of the discussion coupled with the fact that I was dressed casually and did not look like a 'teacher' or a person in authority helped the participants to feel more at ease to 'open up' and engage in meaningful ways.

Some of the teacher interviews also proved problematic. First, a few of the participants were suspicious and unwilling to be recorded while some others were reticent to speak openly because they were afraid of who might listen to the recording. Indeed, one teacher explained that she did not like the idea of her voice being listened to in case she said something silly or did not give the correct answers. In a similar vein, another teacher asked the following: "I have read the information sheet and would be happy to help but can you do it without recording me? Will the head teacher listen to the recordings?" In such cases, I reassured them that everything in the interview would be kept strictly confidential and that they and their respective schools would never be identified by name or in any way that might allow others to identify them. It is important to note that all the above concerns were outlined on the participant's information sheets. However, it was worthwhile to reassure the teachers in order to gain their trust.

Secondly, some of the participants commented that they were frustrated with the language debate and were, what I can only describe as, hostile and defensive to any questions that were related to the use of JC in science teaching and learning. For instance, Irene said: 'I am willing to participate as long as you don't ask me any nonsense about using patwa in my lessons'. I informed her that I was interested to hear her views on all aspects of language usage in science discourse, including the use of JC. After which, she respectfully withdrew her participation from the study.

\section{Positionality: 'Insider' or 'Outsider'?}

In this research study, my personal and professional experiences were factors that influenced the choice of the research problem. I had been both a student and a teacher in Jamaican schools and can identify and empathise with many of the issues related to 
school science instructions and language ideologies. Throughout my adult life, I have both accepted and rejected the prevailing view that JC is a bastardised substandard dialect and that JSE was the measure of intellect and achievement. It is these experiences, I believe, that make the issues of science instructions and language especially urgent and compelling.

In some respects, having a similar cultural, linguistics, ethnic and national heritage as the participants proved advantageous and gave me more rapid access to data which might have eluded an 'outsider' researcher. Firstly, the participants felt more at ease talking to me because they identified me as a fellow Jamaican and hence afforded me a degree of social and cultural proximity. The participants believed that I could comprehend their problems and would be able to narrate their experience in a genuine manner. Nevertheless, on a few occasions I felt the need to distance myself from the participants so that I could communicate their experiences as impartially as possible.

Secondly, similar advantages arose from my familiarity with the language situation as explained above. For this reason, I spoke in both JSE and JC, as appropriate, and encouraged the participants to speak in either or a mixture of both languages if they so desired. Nevertheless, it is perhaps fair to say that while most of the students found the process rewarding and empowering, some found the experience intimidating at times and, consequently, were incoherent or gave conservative responses to some of the salient issues raised in the discussions.

\section{The findings from the student interviews}

Throughout the data, statements by students made it obvious that they held negative attitudes towards the use of JC, were it to be adopted as the medium of instruction in the classroom and the language of science textbooks. Moreover, there seemed to be a lack of recognition of the existence of JC as a discrete language. It was clear that many of the participants considered JC to be a corrupted and inferior 'dialect' of the more prestigious lexically related standard, a version of English which had to be corrected by the education system. Thus, it was not surprising that pejorative terms such as 'broken English', 'back yard talk' and 'bad English' were routinely used to describe JC throughout the interviews. For example, one student (Nyree-all names are pseudonyms) expressed that she 'wouldn't feel good about writing a book in Creole cause you have to remember that Jamaican patwa is a broken language mix with English'. In a similar vein, Patrice voiced that 'JC is no more than a form of "broken English" which only should be used when we are talking to friends and families'. Nyree's and Patrice's statements clearly suggest that they do not recognise JC as an independent language, but rather as one that exists only relative to JSE. These findings are not surprising and mirror those of Hubert Devonish and Otelemate Harry (2004) and Daniel Jettka (2010), all of whom highlighted the pervasive negative attitude towards JC.

Many of those who expressed negative attitudes towards the use of JC in the curriculum offered familiar reasons, such as the inferiority of JC with respect to JSE and economic and social limitations. For instance, one student (Ann)'s attitude towards the use of the vernacular finds expression in her view that "Creole is "back yard talk" and not a real language. The use of Creole shows a lack of ambition and makes you unemployable as no one will employ you when you speak Creole'. So too for Barbara who said 'To get a good job, you need to speak good English. That is why I am totally against using patwa in schools. It's just ridiculous'. 
Two points are particularly noteworthy. Embedded within Ann's and Barbara's analyses is a conception that in Jamaica, languages, as is the case for social class and race (see Thomas 2014), exist in a hierarchy. In this situation, JSE is held in high esteem and has become culturally more powerful than the Indigenous original (JC) which is consequently devalued. This is confirmed by Devonish and Carpenter's (2007) and Craig's (2006) evaluation of the ethnolinguistic hierarchy of Jamaica, according to which JC constitutes the lowest variety.

Another important question concerns issues related to social class. Implicit in Ann's and Barbara's responses is the notion that there is a direct relationship between social class and language use. In this formulation, the use of JC inhibits social mobility whilst the acquisition of JSE is viewed as an apparent passport to higher status. This is an interesting view and one that is consistent with Bryan (2010) who argues that in the Jamaican context language and speech are clear social indicators.

Lesley Milroy and Mathew Gordon (2003) argue that socially highly valued language forms constitute symbolic capital which is potentially convertible into economic capital. Thus, the ability to speak JSE fluently underpins the successful acquisition of 'white-collar' jobs. The assumption made here is that procurement of these jobs constitutes upward mobility. Such linguistic imperialism, which emerged from the colonial system as a hegemonic tool, found itself with an intellectual legitimacy that has since been used to justify class domination. One deleterious consequence of this pattern of thought is that it projects an increasingly tenuous ideology that reinforces and endorses inequalities between classes.

At the same time, some of the interviewees acknowledged the importance of JC insofar as it relates to culture and identity. For instance, one student (Janice) said:

Even though I don't think teachers should be teaching in patwa in the classroom, patwa is still part of our Jamaica culture. It is important for cultural events such as festival. Also, our musicians use patwa in their songs and everybody knows they are Jamaicans when they travel.

Along similar lines, another student (Robert) asserted that:

I wouldn't feel good about it [using JC as the language of science textbook] ... a think if you only going to make it only Jamaican based and appreciating you culture you can write it there but a think that would have to be more a culture thing, a cultural setting more than a science setting because when you learning science you not only learning to be local you learning to be international ...

Evidence of JSE as a hegemonic language was pervasively present throughout the discussions with the students. Indeed, many of them supported the use of JSE as the sole medium of instruction because they saw it as a powerful economic tool for development and commerce in an increasingly globalised world. For example, one student (Tajay) expressed the view that:

English should be used in schools because it is the language spoken by some of the world's largest countries and taught by others as a second language. So, in the business world it is very important.

Another student (George) said:

English is a universal language and countries like ours have to depend on English for trade on the global scale to help economic development. Therefore, it is important for us to be good at it to get jobs. 
Yet another important point raised by the students' discussion concerning hegemonic ideologies deals with issues surrounding the association between speakers of JSE and intelligence. Pertinent to this discussion is the argument put forward by controversial linguist John Honey (1997) who dismisses the assertion that all languages are 'equally good' while at the same time promotes the superiority of standard English to other language forms. In his view, people who speak or write standard English, possess a more extensive range of vocabulary than their non-standard English counterparts and hence are more discerning and knowledgeable.

As insidious and as misleading as such conjectures are, Honey's assertion seems to resonate with some of the participants who sided with the view that speakers of JSE were more articulative and perspicacious than JC speakers and consequently are likely to be successful. For example, Kameka said:

I don't agree with mi teacher using patwa to teach science; it just wouldn't sound intelligent ... People who can talk English good are more intelligent than people who use patwa.

Another participant (Joe) put it this way:

When people talk patwa especially on TV them sound vulgar and dunce but everybody will listen to the ones who a talk English cause dem sound more intelligent.

These statements highlight an ideological acceptance of the hegemonic order. Such beliefs, which denigrate the value of JC, illustrate the effectiveness of the ideology that has shaped our view of language in our society.

\section{Findings from the teacher interviews}

There is substantial evidence from the teacher interviews to suggest that they held ambivalent attitudes to language use in science classrooms. These findings are triangulated with the ones that emerged from the students' group discussions. Many of the science teachers vehemently rejected the notion of JC as the medium of instruction because they consider it a 'bastardised' language with restricted social functions and reduced grammatical categories. They felt that the education system is best served by teaching students JSE, using it as a medium for teaching scientific literacy as well as using it as the sole medium of instruction. In this respect, the teachers' views serve to reproduce the prevailing linguistic status quo of the dominant class and the wider society. Consequently, no effort has been made to promote language consciousness amongst the populace. Devonish and Harry (2004) observed that a significant majority of the Jamaican population have adopted the linguistic order and frown upon the use of JC (in any form), particularly in the educational system. Such reservations were more prominent in the private high schools where teachers were vehemently opposed to the use of JC in education. Indeed, one teacher (Jill) expressed anger and outrage that researchers, such as myself, seem to have an obsession with this 'gibberish "palawala" nonsense'. The education system, she continued, 'would be better served if more time was invested in teaching students to write proper English'.

Still, another teacher (Gail) asserted that she 'didn't have much time to entertain this "patwa" foolishness'. Such derogatory views are by no means surprising, since they are in line with the findings from the students' interviews, and support the conclusions drawn by researchers such as Bryan (2010) and Simmons-McDonald (2006). These authors have drawn specific attention to some of the pertinent issues surrounding the negative image 
of JC and the causes that have hindered the integration of the language in the education domain.

The perception that JC is a deviant dialect of JSE and therefore inappropriate for the purposes of education was the prevalent position for most teachers. Take, for instance, the following comment by Jasmine when she was asked about the use of JC for science instruction: 'ha ha [laugh out loud], teach JSE to our students? JC is 'bad language'; it serves no purpose beyond the airport'. Jasmine's views found support from one of her colleagues, Christine:

It's absurd to use Creole in science classes, primarily because it is quite unfit to raise the educational level. Creole is too primitive; my students would be unable to read and write it. Furthermore, Creole is not even a language; it is a local dialect. Until our language $[\mathrm{JC}]$ is accepted at the level of other languages, where other people in other country can study it [pause] then you can say it really is a true language.

Another teacher (Janet), weighing in on the issue, rejected the use of JC as the main vehicle of communication in the class as she believes that the problem of JSE proficiency was a result of poor resources and inadequate professional development of teachers. She believed that stronger emphasis should be placed on the teaching of JSE and in helping students to move from using the native language to understanding the rules of JSE. In so doing, students, she contended, will become more adept at using JSE. According to Janet, using JC as the medium of instruction would be akin to saying 'we have failed to impart our accepted language of English, so we are giving up. This one can't work, so let us find another one that can work'.

The teachers' dissatisfaction towards questions related to the use of JC as the medium of instructions in classrooms was not conveyed solely through dialogue but by non-verbal signals; what John and Angela Rickford (Rickford and Rickford 1976) described as 'kinesic makers', such as body language, the use of the 'eye-cutting' and 'teeth-kissing'. In Jamaican communities, the act of teeth-kissing is a ubiquitous practise, used to express condemnation or displeasure with an issue 'by making a sound through the act of sucking air through one's teeth' (Rickford and Rickford 1976 p. 20). Peter Patrick and Esther Figueroa (2002) point out that sounds of greater intensity are understood as expressing stronger or more overt feeling of contempt or annoyance. Similarly, Rickford and Rickford (1976) describe eye-cutting as a visual gesture initiated by making eye contact with someone or something, then quickly closing one's eyes and turning or tossing them to one side. The eye-cutting gesture denotes resentment, irritation and intolerance of the person at whom it is focused.

During the interviews, I noted on several occasions when both these gestures were used. For instance, one teacher (Shariska) showed her irritation by kissing her teeth when she was asked if English proficiency was important for success in science. Shariska responded: 'Very much so'. When pressed further, she replied sharply:

How could it not be? [teeth-kissing] The content in the textbook is in Standard English, so if we are going to have textbooks written in Standard English, why wouldn't we not teach in Standard English? Can you just imagine a textbook, a science textbook or whatever subject, and you have in the corner, mi sey you mustn't nyam inna the lab [you should not eat in the lab]. How would that get across to the children? [eye-cutting followed by teeth-kissing]. That just doesn't make sense.

The message from the above quotation is explicit and unequivocal-a clear rejection of the use of JC as a medium of instruction in science education. Undoubtedly, Shariska's 
comments ignore the value of students' home language in providing language-rich and contextualised learning experiences. Moreover, they reveal the ambiguity that still exists about JC. On the one hand, JC is lauded by many as the language of cultural vitality, while at the same time its regular use in relatively prestigious domains is not encouraged. Perhaps such a prevailing negative attitude towards $\mathrm{JC}$ is a result of the inability of experts in the field to adequately demonstrate the kinds of affordances that languages such as JC may offer science learners (Warren, Ballenger, Ogonowski, Rosebery, Hudicourt-Barnes 2001).

However, several teachers did in fact endorse the use of JC as the medium of science instructions, albeit in a restricted context. For example, Bibi commented:

Personally [pause] I think it should be present in the text book and it should be present in the syllabus. Why? [pause] Because many times you are trying to explain something to the students and they will not totally get it in English. But, if you use the patwa they can relate to those words. You might say this is what the word is in patwa and this is it in English. For example, in patwa one might say "Di day a gwan good." You can tell them that in English it is "This is a good day ". In this way the students will be able to relate their patwa to the English to help them read better. Also, the part of the book that says 'vocabulary' or 'key terms' should have the patwa words beside the English words.

Implicit in Bibi's observation is a view that promotes the use of both languages in science instructions and which mirrors the aims of the Bilingual Education Project (2004), which outline a strategy for the formal use of JSE and JC in primary schools. There is some merit in this position, since teaching students in both JC and JSE will valorise their home language, while providing a framework that will make the acquirement and adeptness of JSE more achievable. However, such transitional approaches, which are prevalent in countries like the USA, have tended to be less successful in teaching both the standard language and raising the minoritized language to a more prestigious position. Paulston (1975) blames these failures on the inability of bilingual models to address social class issues in language education. She argues that although the presence of non-standard languages in the classroom may provide some reassurance, speakers will still receive powerful messages that their languages are restricted and less useful. Thus, unless class differences are recognised and efforts to reduce or eliminate them are undertaken, such programmes will have limited success in Jamaican classrooms.

In similar vein, Aldinero supported the use of JC but with some reservation:

The students like when I use Creole because using it makes the lessons interesting.

Speaking Creole can better bring across a point with more clarity and understanding.

However, at each endpoint of a statement I translate into Standard English.

Embedded within Aldinero's description is a model that acknowledges the positive impact of the native language on science learning while at the same time foregrounding the significance of JSE as the language of development, modernisation, and scientific and technological advances. At a surface level, this is a welcome model as it encourages the development of bi-literacy and bilingualism. However, such a description perpetuates the hegemony of JSE, since both languages do not occupy a similar status in the classroom context.

Throughout the interviews, it was evident that JSE held a hegemonic position in the science classroom. It is probably fair to say that most teachers considered it as a language which students are expected to internalise and accept as exigent and indisputable. This was apparent from the teachers' response to a question about which language they use most often in their teaching. Unsurprisingly, JSE was reported as the language used most of the 
time and one that seemed important to the teachers. Indeed, the phrase 'all the time' was repeated continually in relation to JSE. For example, Gail said: 'I try my best to use Standard English all the time. If the students say something in patwa, I get them to repeat it in English', while Joan asserted: 'I use English in every situation and every context of my teaching' Others did not go so far but employed words such as 'frequently', 'often', 'regularly', and 'normally' to describe their use of JSE for science instructions and discourse.

\section{Concluding remarks}

The results suggest that despite evidence that attitudes towards JC are changing, it is clear from the student and teacher interviews that JSE continues to dominate scientific discourse in Jamaican classrooms. But, what are the repercussions for scientific understanding and literacy? Such a question brings into focus a tension between content area instruction and English proficiency development. Too often, science instruction have been too focussed on the acquisition of JSE rather than promoting specific forms of scientific discourse which facilitate student's participation (Lodge 2017). While there is some truth in the argument that science content instruction provides a meaningful context for developing JSE proficiency, science needs to be valued not just as a means for teaching JSE but as a way of knowing and thinking about the natural world.

Consideration must hence be given to those areas of science instruction where JC can serve as an intellectual resource, so that Creole-speaking children can construct meanings based on their linguistic and cultural experiences. The educational benefits of such consideration have been highlighted in Hazel Simmons-McDonald (1996) assessment of language practices in Jamaican classrooms. Simmons-McDonald found that JC speaking children use their cultural and linguistic resources to support understanding of issues in science. For example, in one science lesson both the teacher and her students spoke JC as they discussed the changes of state in water. The teacher drew on the students experience of eating a 'sky juice' (dry ice) to illustrate the process of sublimation. Such a discussion demonstrates how student's social discourse can be used as resources to support deep intellectual engagement and understanding.

Furthermore, studies conducted by the Cheche Konnen Centre in the USA (Rosebery and Warren 2008; Warren and Rosebery 2011) have underscored the extensive teaching opportunities that may be drawn from using Haitian Creole students' linguistic repertoire to negotiate understanding of scientific concepts and principles employing an enquiry-oriented approach to explore student's discourse processes and practices in scientific investigations. The findings suggest that students, utilise their linguistic resources 'not merely as a context for understanding scientific phenomena but as a perspective through which to create possibilities for both seeing and encountering the phenomenon differently' (Warren, Ballenger, Ogonowski, Rosebery, Hudicourt-Barnes 2001, p. 532). The findings also indicate that it is predominantly children with English as a second language who draw on the proficiency and resources of their first language when engaging with school science in a way which is beneficial to them.

What is clear from the preceding discussion is the paramount role of the teacher in facilitating effective discourse in the science classroom. The need for teachers to be able to negotiate JC-based discourse in a sensitive and enlightened way highlights the importance of it being included as a focus in teacher training. If teachers are knowledgeable about JC as a language system in its own right, negative attitudes and behaviours amongst teachers 
are likely to be less frequent and more likely to be challenged when they arise. Teachers would consequently be more likely to be tolerant of JC 'errors' and able to discriminate between miscues which merely reflect the only language resource available to students and those which require instructional attention because they violate syntactic and/or semantic acceptability. Teacher rejection of JC can lead to Creole-speaking children being unable to express themselves adequately in science, and other subjects.

Therefore, the above narrative emphasizes the urgent need for the development of professional models focused on science teachers' understanding of the role and value of JC in the classroom and its place in negotiating children's understanding and subsequent discourse in science education. After all, if teachers aim to promote an inclusive learning environment for all students, respect and understanding of the culturally rich, linguistic heritage Jamaican children come from and operate within is imperative to effective teaching in any classroom.

Open Access This article is distributed under the terms of the Creative Commons Attribution 4.0 International License (http://creativecommons.org/licenses/by/4.0/), which permits unrestricted use, distribution, and reproduction in any medium, provided you give appropriate credit to the original author(s) and the source, provide a link to the Creative Commons license, and indicate if changes were made.

\section{References}

Alleyne, M. (2005). The construction and representation of race and ethnicity in the Caribbean and the world. Kingston: University of the West Indies.

Babaci-Wilhite, Z. (2016). The use of local languages for effective science literacy. In Z. Babaci-Wilhite (Ed.), Human rights in language and STEM education (pp. 3-15). Rotterdam: Sense Publishers.

Baker, C. (2011). Foundations of bilingual education and bilingualism. Bristol: Multilingual Matters.

Barac, R., \& Bialystok, E. (2011). Cognitive development of bilingual children. Language Teaching, 44(1), 36-54. https://doi.org/10.1017/S026144481000339.

Brock-Utne, B. (2016). English as the language of science and technology. In Z. Babaci-Wilhite (Ed.), Human rights in language and STEM education (pp. 111-127). Rotterdam: Sense Publishers.

Bryan, B. (2010). Between two grammars: research and practice for language and teaching in a Creolespeaking environment. Kingston: Ian Randle.

Christie, P. (2003). Language in Jamaica. Kingston: Arawak Publication.

Craig, D. R. (2006). The use of the vernacular in West Indian education. In H. Simmons-McDonald \& I. Robertson (Eds.), Exploring the boundaries of Caribbean Creole languages (pp. 99-117). Kingston: University of the West Indies Press.

Crystal, D. (1988). The English language. London: Penguin.

Cummins, J. (1992). Knowledge, power and identity in teaching English as a second language. In F. Genesee (Ed.), Educating second language children. Cambridge: Cambridge University Press.

Devonish, H. (1986). Language and liberation: Creole language politics in the Caribbean. London: Karia Press.

Devonish, H., \& Carpenter, K. (2007). Full bilingual education in a creole situation: the Jamaican bilingual primary education project. Occasional Paper, No. 35. Society for Caribbean Linguistics. St Augustine: University of the West Indies.

Devonish, H., \& Harry, O. G. (2004). JC and Jamaican English: Phonology. A Handbook of Varieties of English, 1(1), 450-480.

Drayton, K. (1990). 'The most important agent of civilisation': teaching English in the West Indies. In J. Britton, R. E. Shafer, \& K. Watson (Eds.), Teaching and learning English worldwide (pp. 200-225). Philadelphia: Multilingual Matters.

Honey, J. (1997). Language is power: the story of standard English and its enemies. London: Faber and Faber.

Jettka, D. (2010). The language situation of Jamaica language education policy in the tension between standard Jamaican English and Jamaican patwa. Retrieved from http://www.daniel-jettka.de/pdf/ JETTKA-The_language_situation_of_Jamaica.pdf. Accessed 14 Jan 2019. 
Lodge, W. (2017). Science learning and teaching in a Creole-speaking environment. Cultural Studies of Science Education, 12(3), 661-675. https://doi.org/10.1007/s11422-016-9760-6.

Lodge, W. (2018). The accessibility of science instructions to Jamaican students. Unpublished Ph.D study, UCL, Institute of Education, London.

Macswan, J. (2000). The threshold hypothesis, semilingualism, and other contribution to a deficit view of linguistic minorities. Hispanic Journal of Behavioral Science, 22(1), 3-45. https://doi. org/10.1177/2F0739986300221001.

Mair, C. (2013). The world systems of Englishes: Accounting for the transnational importance of mobile and mediated vernaculars. English World-Wide, 34(3), 253-278. https://doi.org/10.1075/ eww.34.3.01mai.

May, S. (2008). Bilingual/immersion education: What the research tells us. In J. Cummins \& N. Hornberger (Eds.), Bilingual Education (pp. 19-34)., The encyclopaedia of language and education New York: Springer.

Milroy, L., \& Gordon, M. (2003). Sociolinguistic: methods and interpretation. London: Blackwell.

Ovando, C. J., \& Collier, V. P. (1985). Bilingual and ESL classrooms: teaching in multicultural contexts. New York: McGraw-Hill.

Patrick, P. L., \& Figueroa, E. (2002). Kiss-teeth. American Speech, 77(4), 383-397. https://doi. org/10.1215/00031283-77-4-383.

Paulston, C.B. (1975). Ethnic relations and bilingual education: Accounting for contradictory data. Retrieved from https://files.eric.ed.gov/fulltext/ED125253.pdf. Accessed 15 Apr 2019.

Pennycook, A. (2014). The cultural politics of English as an international language. London: Routledge.

Phillipson, R. (2001). English for globalisation or for the world's people? International Review of Education, 47(3), 185-200. https://doi.org/10.1023/A:1017937322957.

Phillipson, R. (2008). Linguistic imperialism continued. London: Routledge.

Rickford, J. R., \& Rickford, A. E. (1976). Cut-eye and suck-teeth: African words and gestures in new world guise. The Journal of American Folklore, 89(353), 294-309.

Rosebery, A., \& Warren, B. (2008). Teaching science to English language learners: Building on students' strengths. Arlington: National Science Teachers Association.

Schulzke, M. (2014). The prospects of global English as an inclusive language. Globalisations, 11(2), 225-228. https://doi.org/10.1080/14747731.2014.904173.

Simmons-McDonald, H. (1996). Language education policy: the case for Creole in formal education in St. Lucia. In P. Christie (Ed.), Caribbean language issues: Old and new (pp. 120-142). St. Augustine: University of the West Indies.

Simmons-McDonald, H. (2006). Attitudes of teachers to St. Lucian language varieties. Caribbean Journal of Education, 28(1), 51-84.

Suarez, D. (2002). The paradox of linguistic hegemony and the maintenance of spanish as a heritage language in the United States. Journal of Multilingual and Multicultural Development, 23(6), 512 530. https://doi.org/10.1080/01434630208666483.

Thomas, E. (2014). Education in the Commonwealth Caribbean and Netherlands Antilles (Vol. 22). London: Bloomsbury Publishing.

Tupas, R., \& Rubdy, R. (2015). Introduction: From world Englishes to unequal Englishes. In R. Tupas (Ed.), Unequal Englishes (pp. 1-17). London: Palgrave Macmillan.

Warren, B., Ballenger, C., Ogonowski, M., Rosebery, A. S., \& Hudicourt-Barnes, J. (2001). Rethinking diversity in learning science: The logic of everyday sense-making. Journal of Research in Science Teaching, 38(5), 529-552. https://doi.org/10.1002/tea.1017.

Warren, B., \& Rosebery, A. (2011). Navigating interculturality: African American male students in the science classroom. Journal of African American Males in Education, 2(1), 98-115.

Publisher's Note Springer Nature remains neutral with regard to jurisdictional claims in published maps and institutional affiliations.

Wilton George Lodge has been involved in STEM education for the past 20 years. He has worked in various secondary schools in England and in the Caribbean. He is the holder of a Ph.D. in education from the University College London, Institute of Education. Wilton is particularly interested in socio-linguistics issues, scientific literacy, science and social justice, science education and creativity, chemistry education and pedagogy in science language. He is also the holder of a Bachelor of Education degree from the University of the West Indies and a Master of Arts degree from the University College London, Institute of Education. 